\title{
Constraining past accumulation in the central Pine Island Glacier basin, West Antarctica, using radio-echo sounding
}

\author{
Nanna B. KARLSSON, ${ }^{1,2}$ Robert G. BINGHAM, ${ }^{3}$ David M. RIPPIN, ${ }^{4}$ \\ Richard C.A. HINDMARSH, ${ }^{5}$ Hugh F.J. CORR, ${ }^{5}$ David G. VAUGHAN ${ }^{5}$ \\ ${ }^{1}$ Centre for Ice and Climate, Niels Bohr Institute, University of Copenhagen, Copenhagen, Denmark \\ E-mail: nbkarlsson@nbi.dk \\ ${ }^{2}$ Department of Geography, University of Hull, Hull, UK \\ ${ }^{3}$ School of GeoSciences, University of Edinburgh, Edinburgh, UK \\ ${ }^{4}$ Environment Department, University of York, Heslington, York, UK \\ ${ }^{5}$ British Antarctic Survey, Natural Environment Research Council, Cambridge, UK
}

\begin{abstract}
The potential for future dynamical instability of Pine Island Glacier, West Antarctica, has been addressed in a number of studies, but information on its past remains limited. In this study we use airborne radio-echo sounding (RES) data acquired over Pine Island Glacier to investigate past variations in accumulation pattern. In the dataset a distinctive pattern of layers was identified in the central part of the glacier basin. We use these layers as chronological identifiers in order to construct elevation maps of the internal stratigraphy. The observed internal layer stratigraphy is then compared to calculated stratigraphy from a three-dimensional ice-flow model that has been forced with different accumulation scenarios. The model results indicate that the accumulation pattern is likely to have changed at least twice since the deposition of the deepest identified layer. Additional RES data linked to the Byrd ice core provide an approximate timescale. This timescale suggests that the layers were deposited at the beginning of or during the Holocene period. Thus the widespread changes occurring in the coastal extent of the West Antarctic ice sheet at the end of the last glacial period could have been accompanied by changes in accumulation pattern.
\end{abstract}

KEYWORDS: Antarctic glaciology, ground-penetrating radar, ice-sheet modelling, radio-echo sounding

\section{INTRODUCTION}

The long-standing hypothesis (e.g. Mercer, 1978; Hughes, 1981) that the West Antarctic ice sheet (WAIS) is potentially unstable and could be a major contributor to eustatic sealevel rise (e.g. Bamber and others, 2009; Joughin and Alley, 2011) has gained momentum over the past two decades, with satellite observations consistently highlighting major changes occurring across the ice sheet. Glacier catchments flowing to the Amundsen Sea have undergone some of the most significant changes (e.g. Rignot, 1998; Shepherd and others, 2002; Rignot and others, 2008; Pritchard and others, 2009; King and others, 2012), suggesting this region is especially sensitive to environmental forcing. Changes in velocity throughout Pine Island Glacier (PIG), and episodic inland retreat and thinning of its grounding line, are well documented from satellite observations (Rignot, 1998; Shepherd and others, 2002; Thomas and others, 2004; Wingham and others, 2009; Park and others, 2013) and from ground-based GPS measurements (Scott and others, 2009).

These observations have, in recent years, motivated several numerical modelling studies aimed at identifying systematic sensitivities in PIG's behaviour (e.g. Gladstone and others, 2012; Larour and others, 2012), and targeted surveys of its basal topography and conditions (Vaughan and others, 2006; Smith and others, 2012, 2013), all with a view to predicting the possible response of PIG to climate forcing and its contribution to sea level over a future timescale of up to 200 years (cf. Joughin and others, 2010). To support these initiatives we need studies that can shed light on the past behaviour of PIG prior to modern observations, thereby placing the behaviour over the last three decades in a longerterm perspective and providing improved understanding of the overall stability of this region of Antarctica. This paper therefore uses the internal layering captured by radio-echo sounding (RES) over PIG to investigate long-term (i.e. millennial-scale) changes in accumulation in the catchment.

Internal layering in ice sheets - the RES expression of dielectric contrasts in ice induced by changes in density, impurity, acidity or crystal-fabric orientations (e.g. Miller, 1981; Fujita and others, 1999; Eisen and others, 2007) - is increasingly being used in glaciology to elucidate ice-flow and mass-balance histories (e.g. Siegert, 1999; Rippin and others, 2003; Ng and Conway, 2004; Bingham and others, 2007; Waddington and others, 2007; Neumann and others, 2008; Hindmarsh and others, 2009; MacGregor and others, 2009; Leysinger Vieli and others, 2011). Underpinning all these studies is the acceptance that internal layers are isochrones whose stratigraphy records variations in accumulation, ice flow and, in some cases, basal melting (e.g. Buchardt and Dahl-Jensen, 2007). Previous work on PIG using radio-echo sounded internal layering has focused on its use to reconstruct ice-flow dynamics, and has shown that the spatial configuration of ice flow across the catchment has changed little since the deposition of the layers (Karlsson and others, 2009, 2012). To date, however, the internal layering recovered across the region by RES has generally not been utilized in ice-sheet modelling for purposes of retrieving accumulation information. Instead present-day accumulation has been derived from inversion techniques (e.g. Arthern and others, 2006), or inferred from point 

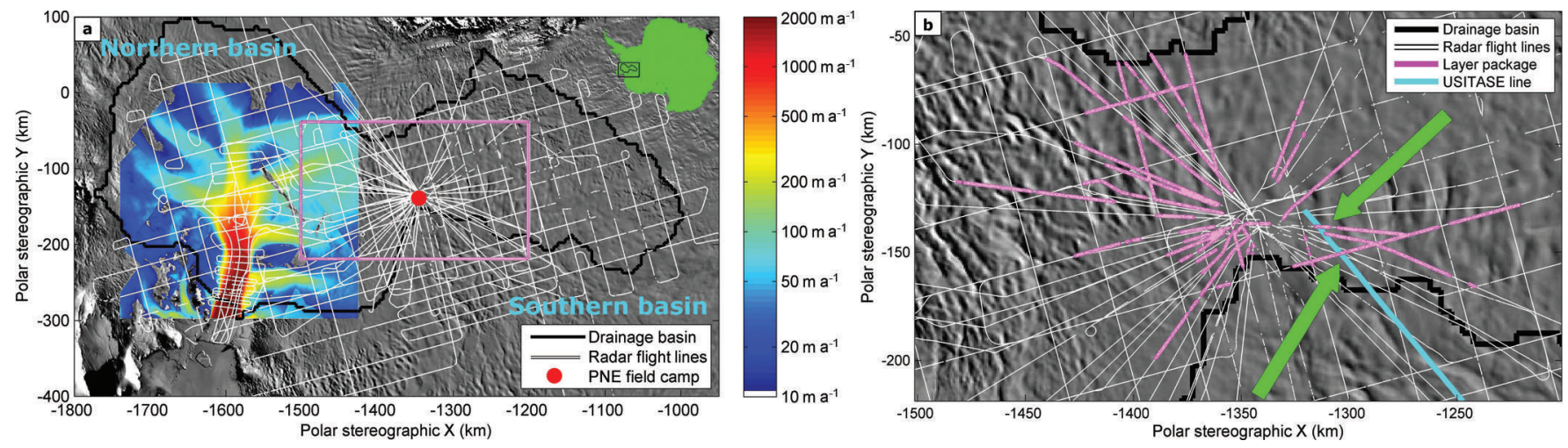

Fig. 1. (a) Map of PIG basin with the basin boundaries outlined in black. Surface velocities derived from interferometric synthetic aperture radar (InSAR) are shown for context (colour shading) (Rignot, 2006) and MODIS (Moderate Resolution Imaging Spectroradiometer) Mosaic of Antarctica imagery as background (Haran and others, 2006). The RES flight lines are shown in white. (b) Zoom-in on the magenta box in (a) showing the extent of the layer package (magenta) and the United States International Trans-Antarctic Scientific Expedition (USITASE) line where the 17.5 ka layer could be identified (cyan). The intersection points of layer 2 and the 17.5 ka layer are marked with green arrows. The ice-flow model domain is equivalent to the drainage basin.

measurements made in nearby regions (e.g. Frezzotti and others, 2013), sometimes coupled with climate models (e.g. Van de Berg and others, 2006).

In this study we have mapped two internal layers in the central part of the PIG basin. In other words, we have information on the depths of two isochrones. We compare the depths of these observed isochrones with modelled isochrones generated by a three-dimensional (3-D) ice-flow model, and use this to retrieve information on past accumulation patterns. The agreement between the modelled isochrones and the observations is evaluated for each model scenario. We note our approach only provides information on which of the predefined accumulation patterns gives the best fit to the observed data, rather than constituting a more formalized inverse approach which would independently find the best parameters. The latter approach, while it would be optimal, is highly challenging to implement; our approach here nevertheless gives us firstorder insights into the past history of accumulation patterns for the central PIG basin.

\section{RADIO-ECHO SOUNDING DATA}

The RES data used here were acquired in the 2004/05 austral season during an integrated aerogeophysical campaign that was designed primarily to map the subglacial topography of PIG (see Vaughan and others, 2006) and interpret its geological setting (Jordan and others, 2010; Smith and others, 2013). The survey operated out of a temporary airstrip, the 'PNE' field camp $\left(77^{\circ} 34^{\prime} \mathrm{S}, 95^{\circ} 56^{\prime} \mathrm{W}\right)$, situated in central PIG between its slower-flowing southern basin and the fast-flowing northern basin that contains the ice stream's main trunk and major tributaries (Fig. 1). The airborne platform was equipped with the ice-sounding RES system PASIN (Polarimetric Airborne Survey INstrument), a dual-frequency carrier-wave GPS for navigation, a radar altimeter, wing-tip magnetometers and a gravity meter. During data acquisition the position of the aircraft was known with an accuracy better than $\pm 1 \mathrm{~m}$. The PASIN instrument collected data with a transmit power of $4 \mathrm{~kW}$ around a central frequency of $150 \mathrm{MHz}$, with a $4 \mu \mathrm{s}, 10 \mathrm{MHz}$ chirp (e.g. frequency sweep 145-155 MHz). To obtain ice thickness information, the velocity of the radar waves within the ice was taken to be $168.374 \mathrm{~m} \mathrm{ss}^{-1}$ with no firn correction (Holt and others, 2006). The firn correction typically alters depths by $\sim 10 \mathrm{~m}$, which is small in the present context where ice thicknesses are of the order of $10^{3} \mathrm{~m}$. While the principal aim of the overall RES survey was to sound the bed and map subglacial topography across PIG, the 'chirp' acquisition also recovered numerous internal layers through the full depth of the ice. More information on the overall survey campaign is provided by Vaughan and others (2006), while Corr and others (2007) and Ross and others (2012) provide supplementary technical information relating to the use of the same integrated aerogeophysical suite deployed elsewhere in Antarctica.

The acquisition of gravity data dictated that the majority of flights were operated at a constant elevation, with most flights across PIG forming a regular $30 \mathrm{~km}$ grid. However, five flights dedicated solely to optimized RES data collection were flown at a constant $150 \mathrm{~m}$ terrain clearance along and across the tributaries and main trunk of PIG (Fig. 1). Both configurations acquired information on internal layering and, while the RES data acquired during the gravity measurements are less clear, a distinctive layer package could still be identified with confidence in a large number of flight lines. Our previous analysis of the continuity of the layers in the PIG basin has shown that many are obscured by fast flow in the main trunk of PIG (Karlsson and others, 2012). This strong flow-directionality, combined with optimization of RES acquisition towards sounding the bed, precludes crosscorrelating individual reflectors between many of the flight lines. However, in the central PIG basin surrounding the PNE field camp, we identified a set of internal layers with a unique signature making it easily identifiable, hereafter termed a 'layer package'. Following previous work (e.g. Hindmarsh and others, 2009) we treat the package as a chronological identifier (in effect, isochrones).

Figure 2 shows an example of the RES data used here. In the image a diffused layer is visible at approximately the middle of the full-depth range. Above the diffused layer there is a strongly reflecting layer and below it another two strongly reflecting layers are visible. This characteristic pattern comprises our layer package. In the following, the uppermost strongly reflecting layer is referred to as layer 1 and the uppermost of the two lower strongly reflecting layers 

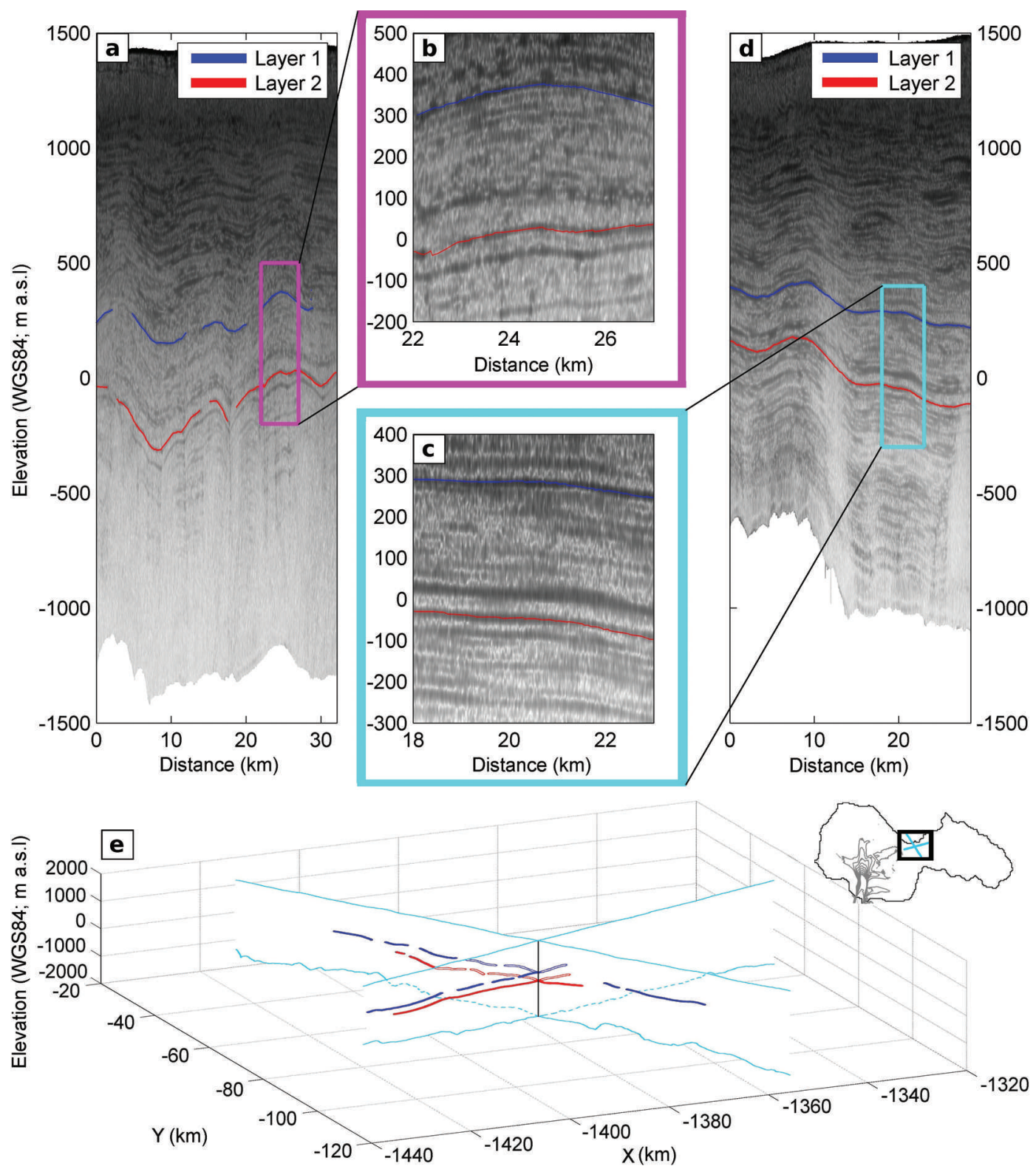

Fig. 2. (a, d) Example of two typical radargrams (or Z-scopes), with close-ups (b, c) of the layer package. (e) An example of two intersecting radargrams, each with the layer package identified.

is referred to as layer 2. Layers 1 and 2 were traced using a semi-automated tracing routine that followed the local maxima in received reflected power. We have selected these two layers because they were the most consistently visible in the RES data. The overall layer package was detected across central PIG basin along the flight lines shown in magenta in Figure 1. Owing to the configuration of the survey, there were few crossovers of the flight lines in this region. At the crossover points the mean difference in elevation between identified layers was $3.3 \mathrm{~m}$ for layer 1 and $3.0 \mathrm{~m}$ for layer 2 , giving us confidence that the layer package has been identified correctly.

\section{THREE-DIMENSIONAL ICE-FLOW MODEL}

The overall objective of our ice-flow modelling is to estimate the spatial accumulation pattern required to reproduce the two traced layers in the layer package. We concern ourselves only with finding the accumulation pattern that produces the best relative fit, rather than the absolute accumulation rate since that requires information on the ages of the layers.

The model used here, BASISM (the British Antarctic Survey Ice Sheet Model), is a quasi-steady-state model based on the shallow-ice approximation (e.g. Hutter, 1983). The geometry is fixed, and the spatial pattern of the accumulation rate is fixed from run to run. However, when predicting undated layer geometry, the spatial pattern of accumulation rate can be varied by a constant multiplier without altering the computed geometry (Parrenin and others, 2006). The surface and bed topography are on a $2 \mathrm{~km}$ grid generated predominantly from the gridded PASIN data described below, and also using other pre-existing thickness-survey data as now incorporated into BEDMAP2 (Fretwell and others, 2013).

The model domain is the entire PIG drainage basin (outlined in black in Fig. 1) and we assume that the drainage boundaries do not change in time. Throughout the model 


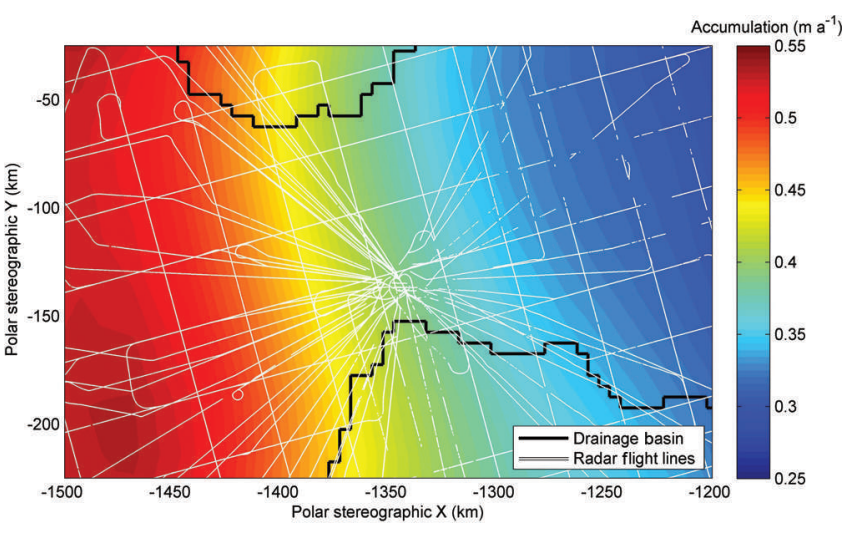

Fig. 3. The modern accumulation pattern from Arthern and others (2006) in the central part of the PIG basin.

runs, the ice thickness is assumed to be constant. This limits the confidence in estimated accumulation rates. Even so, it seems likely that a change in ice thickness in the central part of the basin would be a widespread change (e.g. associated with the end of a glacial period) rather than a local change. The constant ice thickness is therefore less problematic in terms of obtaining relative accumulation patterns, since a change to the whole area would mean a simultaneous thinning of the layers, changing their depth rather than their relative stratigraphy.

Rather than compute the coupling between temperature and vertical variation in the velocity field, we consider end members of plug flow, which corresponds to having deformation at the base (e.g. due to the presence of warm ice), and flow by internal deformation, both with a uniform temperature field. Plug flow represents the vertical variation of velocity where sliding predominates, and thus represents a flow type where ice is streaming. Neither end member includes the full stresses that would be present in ice streams; however, the observed layers are found in the central part of the PIG basin and not the fast-flowing parts of the glacier. The two types of flow should therefore be able to capture the ice-flow dynamics accurately.

The ice-flow model also includes a layer-fitting algorithm. The fitting is achieved by a least-square formulation that is described in more detail by Hindmarsh and others (2009). In this study we quantify the quality of the fit by considering the mean value of the distance $\bar{d}$ (the absolute value of the elevation difference, $d$ ) between observed $\left(z^{\text {obs }}\right)$ and modelled $\left(z^{\text {mod }}\right)$ layer depths:

$$
\bar{d}=\frac{1}{n} \sum_{i=1}^{n} d_{i}=\frac{1}{n} \sum_{i=1}^{n} \sqrt{\left(z_{i}^{\text {obs }}-z_{i}^{\text {mod }}\right)^{2}}
$$

where $n$ is the number of points (i.e. the number of layer picks). We also include the standard deviation of the distance between observations and model results for comparison.

In the following, we outline the basic equations for the ice-flow model but refer readers seeking further details to the more complete description in Leysinger Vieli and others (2007) and Hindmarsh and others (2009). The model solves the mass-balance equation

$$
\frac{\partial H}{\partial t}+\nabla \cdot \mathbf{Q}=a-m
$$

where $H$ is the ice thickness, $a$ is accumulation, $m$ is melt rate and the horizontal flux $\mathbf{Q}$ is defined as $\mathbf{Q}(\mathbf{r}, t)=\overline{\mathbf{u}} H(\mathbf{r}, t)$, where $\overline{\mathbf{u}}$ is the vertically averaged horizontal velocity, $\mathbf{r}$ is the coordinate vector and $t$ is time. The age $X$ of the ice is then solved as an advective equation in three dimensions:

$$
\frac{\partial X}{\partial t}+\mathbf{u} \cdot \nabla_{\mathrm{H}} X+w \frac{\partial X}{\partial z}=1
$$

where $\mathbf{u}$ is the horizontal velocity and $\nabla_{\mathrm{H}}$ is the horizontal gradient. In the following, it is convenient to change coordinate system and work in normalized coordinates in the vertical direction:

$$
\zeta=\zeta(\mathbf{r}, z, t)=\frac{z-b(\mathbf{r})}{H(\mathbf{r}, t)}
$$

where $z$ is the elevation and $b(\mathbf{r})$ the bed topography. With the coordinate change, the surface elevation is set to 1 and the bed to 0 . The horizontal velocity $\mathbf{u}$ can be related to the vertically averaged horizontal velocity from the expression $\mathbf{u}=\overline{\mathbf{u}} v(\zeta, \mathbf{r})$ using a velocity shape function $v$ :

$$
v(\zeta, \mathbf{r})=1 \quad(\mathrm{~S}, \text { uniform plug flow })
$$

$v(\zeta, \mathbf{r})=\frac{n+2}{n+1}\left[1-(1-\zeta)^{n+1}\right]$

(ID, internal deformation)

The equations above describe two situations: uniform plug flow (S) and isothermal internal deformation (ID) with flow exponent $n=3$, i.e. using Glen's law (Glen, 1955; Paterson, 1994). Plug flow simply means that the horizontal velocity does not change with depth while in the case of internal deformation the horizontal velocity decreases with depth following Glen's law.

In order to compute the age-field and generate isochrones, the accumulation pattern needs to be prescribed. Since the model does not include a formal inverse technique, we run the model with the following accumulation patterns in order to find the best match between observed layers and the model results: (i) a uniform accumulation pattern of $1 \mathrm{ma}^{-1}$; (ii) the modern accumulation pattern from Arthern and others (2006) (ranging from 0.1 to $0.6 \mathrm{ma}^{-1}$; Fig. 3); (iii) an accumulation pattern wherein accumulation rate decreases linearly with surface elevation from $0.1 \mathrm{~m} \mathrm{a}^{-1}$ at the highest elevation point to $1 \mathrm{~m} \mathrm{a}^{-1}$; and (iv) an accumulation pattern containing a local high of accumulation (increase of 50\%) centred around the region close to PNE where the observed layer package dips downwards. We chose the different scenarios based on the following considerations: scenario (i) was used to estimate how good a fit could be obtained with a very simple scenario; scenarios (ii) and (iii) are considered to be the most realistic scenarios which could be expected to give better fits than scenario (i); and scenario (iv) was used to check whether the model could produce a better fit with an accumulation pattern forced to mimic the depth of layer 1 .

We also varied the pattern and rate of basal melt using the assumption that the occurrence of basal melting is controlled by thick ice acting as an insulating layer. In reality, other factors (e.g. variations in geothermal heat flux) also influence the basal melt pattern, but we have no means of estimating the local geothermal heat flux in the PIG basin and therefore restrict ourselves to considering ice thickness variations only. Using a uniform accumulation pattern (scenario (i)) we ran the model three times with an increased basal melt rate of $50 \%$ of the accumulation rate in areas 

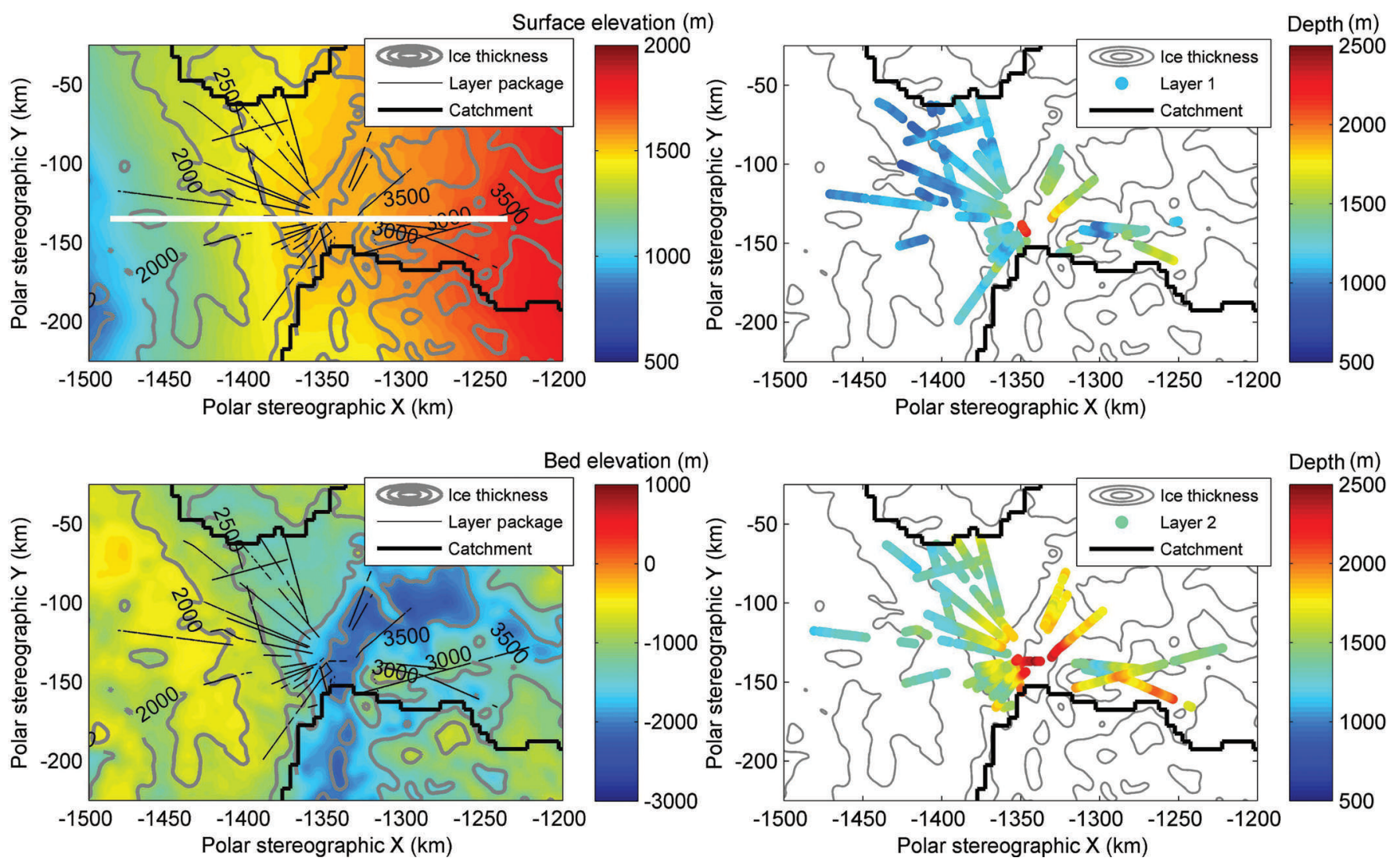

Fig. 4. Left column: Surface and bed topography of the central part of the PIG basin. The white line shows the location of Figure 5. Right column: depths below the ice surface of layers 1 and 2 . The ice thickness is shown as grey $500 \mathrm{~m}$ contours.

where the ice thickness was larger than 2500, 2750 and $3000 \mathrm{~m}$ respectively.

\section{RESULTS}

The overall result of the layer tracing is presented in Figure 4 . Layer 1 has a depth range of $843-2359 \mathrm{~m}$, and layer 2 has a range of $1124-2451 \mathrm{~m}$. As exemplified in Figure 5, the layer depths follow the bed topography to a large extent. In this context it is worth noting two features of the traced layer package. Firstly, moving from south to north across the mapped region, towards a high in the subglacial topography identified by Vaughan and others (2006), the layer package generally decreases in (absolute) depth below the surface of the ice (Fig. 5) in a way that does not completely mimic the bed topography. Secondly, both layers 1 and 2 experience a
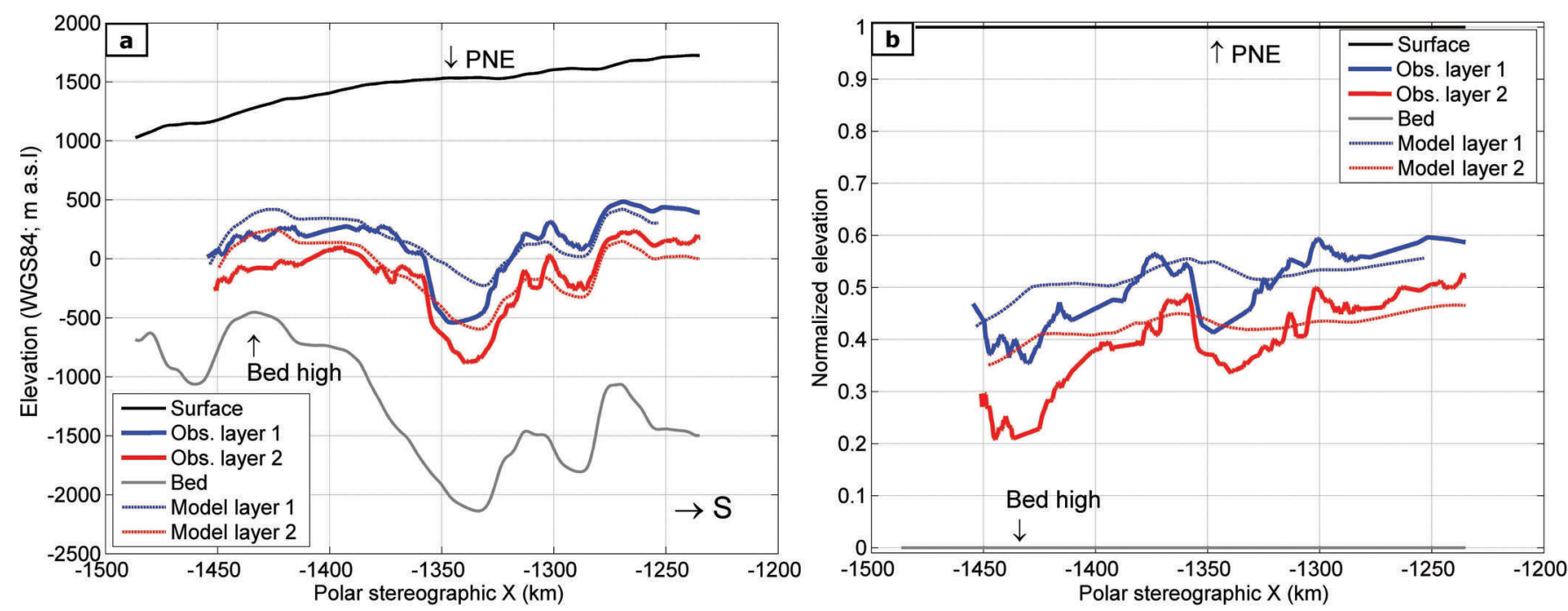

Fig. 5. Elevation (a) and normalized elevation (b) of the surface, bed, layers 1 and 2, and the modelled layers from scenario (i) along a transect crossing the field camp PNE and the bed high (location is shown as a white line in Fig. 4, left). 
Table 1. Results for different accumulation scenarios for fitting the layer package. The flow mode was either prescribed as plug flow (S) or internal deformation (ID). The vertical resolution was 11 gridpoints, and the basal melt was $1 \%$ of the accumulation. The misfit is assessed based on mean distance between observations and model, $\bar{d}$ ( $m$; cf. Eqn (1)), and standard deviation of the distance between observations and model, $\sigma(\mathrm{m})$

\begin{tabular}{llcrcccc} 
Scenario Accumulation pattern & Flow mode & \multicolumn{2}{c}{ Layer 1} & \multicolumn{2}{c}{ Layer 2} \\
& & & $\bar{d}$ & $\sigma$ & $\bar{d}$ & $\sigma$ \\
& & & & & \\
\hline 1 & \multirow{2}{*}{ Uniform accumulation } & S & 83 & 67 & 115 & 88 \\
& & ID & 90 & 71 & 130 & 95 \\
2 & Modern accumulation & S & 108 & 81 & 108 & 91 \\
& & ID & 97 & 81 & 105 & 90 \\
3 & Linear accumulation & S & 100 & 74 & 105 & 87 \\
& & ID & 94 & 76 & 102 & 90 \\
4 & Local accumulation high & S & 66 & 65 & 111 & 89 \\
& & ID & 79 & 68 & 127 & 93
\end{tabular}

notable downward dip within the relative narrowing or 'neck' of the PIG catchment where the northern and southern catchment basins connect (i.e. close to the PNE field camp; Fig. 5). The standard deviation and range of the depth of layer 2 are slightly higher than for layer 1 , which is consistent with the fact that layer 2 has been subjected to more cumulative deformation since it is deeper and thus older than layer 1 (Cuffey and Paterson, 2010).

We now discuss the use of 3-D ice-flow modelling to reproduce the spatial variation in depth of the layer package and thereby to infer accumulation patterns across the region since the deposition of the layer package (Table 1). In the following, all results are from model runs with a basal melt rate of $1 \%$ of the accumulation and with a vertical resolution of 11 vertical gridcells, i.e. with an ice thickness varying between approximately 2000 and $3500 \mathrm{~m}$ (cf. Fig. 4) the vertical resolution is $200-350 \mathrm{~m}$.

The best fit for layer $1(\bar{d}=66 \mathrm{~m}, \sigma=0.024)$ was obtained by introducing a localized accumulation maximum, i.e. scenario (iv). Surprisingly the fit did not improve when changing from scenario (i) (uniform accumulation pattern) to a modern-day accumulation pattern or a linear accumulation pattern (scenarios (ii) and (iii)). We increased the number of vertical gridpoints to 21 and 31 in order to test the robustness of these results to the vertical resolution and found that the conclusions did not change if the vertical resolution was increased.

Table 2. Results for different basal melt scenarios for fitting the layer package. The accumulation pattern was uniform (scenario (i)); the flow mode was plug flow, with a vertical resolution of 11 gridpoints. The misfit is assessed based on mean distance between observations and model, $\bar{d}$ (m; cf. Eqn (1)), and standard deviation of the distance between observations and model, $\sigma(\mathrm{m})$

\begin{tabular}{lcccc}
\hline Melt area & \multicolumn{2}{c}{ Layer 1} & \multicolumn{2}{c}{ Layer 2 } \\
$50 \%$ of acc. & $\bar{d}$ & $\sigma$ & $\bar{d}$ & $\sigma$ \\
\hline$H>2500 \mathrm{~m}$ & 87 & 72 & 117 & 93 \\
$H>2750 \mathrm{~m}$ & 92 & 72 & 121 & 92 \\
$H>3000 \mathrm{~m}$ & 83 & 71 & 117 & 100 \\
& & & & \\
\hline
\end{tabular}

By contrast, for layer 2 both scenarios (ii) and (iii) had a better fit than scenario (i), with scenario (iii) (the linear accumulation pattern) being slightly better than scenario (ii) (the modern-day accumulation pattern). The worst fit was obtained in scenario (iv), where the accumulation pattern was matched to the depth of layer 1 . We increased the vertical resolution and found that the best fit was still obtained with a linear accumulation pattern and the worst fit was still scenario (iv).

Finally, our results showed no improvement in the fit for the three different basal melt scenarios (Table 2). We interpret this as an indication that the variation of basal melt in PIG is not primarily driven by ice thickness. We return to this point in the discussion below.

No scenarios were found that simultaneously decreased the misfit for both layers 1 and 2. We do, however, note the following: it was not possible to improve the fit of layer 1 using a modern or linear accumulation pattern compared to a simple uniform accumulation pattern.

\section{USING THE BYRD ICE-CORE CHRONOLOGY TO ESTIMATE LAYER AGES AND ACCUMULATION RATES}

Age-depth profiles for internal layers, and thus records of ice accumulation, can be constructed using direct calibration with deep ice cores (e.g. Parrenin and others, 2004; Buchardt and Dahl-Jensen, 2007; Huybrechts and others, 2009). However, the absence of any deep ice-core record from (or even close to) PIG leaves us to seek an alternative method for estimating the age of the layer package. For this purpose we refer to a ground-based RES transect collected across central PIG in 2001 completed as part of the International Trans-Antarctic Scientific Expedition (ITASE; Welch and Jacobel, 2003; Jacobel and Welch, 2005; NSIDC data record No. 0264) and accessible from the US National Snow and Ice Data Center (NSIDC). This ITASE transect connects central PIG to the Byrd Station deep ice-core site in central West Antarctica $\left(80.02^{\circ} \mathrm{S}, 119.52^{\circ} \mathrm{W}\right)$. Around Byrd Station, a prominent strongly reflecting layer identified in the ITASE RES profiles (Jacobel and Welch, 2005) corresponds to an acidity anomaly first identified by Hammer and others (1997) and which was dated using the ice-core chronology by Blunier and Brook (2001) to an age of $17.5 \mathrm{ka}$. In the ITASE dataset this 17.5 ka layer was traced all the way to the PIG basin (Fig. 1b). Unfortunately it was not possible to recover the $17.5 \mathrm{ka}$ layer directly from the PASIN data. Part of the explanation for this is the different frequency range of the PASIN radar relative to the ITASE radar $(150 \mathrm{MHz}$ vs $3 \mathrm{MHz}$ centre frequency respectively). The strong acidity signal measured in the Byrd ice core represents a multiple pulsed acidity variation that stretches over 170 years (Hammer and others, 1997), implying that with the $150 \mathrm{MHz}$ frequency this may well show up in PASIN profiles as several reflecting layers, cumulatively creating a weaker signal, rather than the single clear reflector so prominent in the ITASE traverse (personal communication from R. Jacobel, 2010). A further mitigating factor is that the reflection strength of the $17.5 \mathrm{ka}$ layer decreases with distance towards PIG from Byrd Station (Jacobel and Welch, 2005), hence the anomaly may be too weak altogether to be picked up in the PASIN data considering the depth of the layer.

To work around this issue, we use the known depth of the ITASE-imaged $17.5 \mathrm{ka}$ layer in the PIG basin (the $17.5 \mathrm{ka}$ 
layer depth is available as part of the NSIDC dataset) to obtain an estimate of mean accumulation since the time of deposition of the layer. This is done via a simple relation between depth and accumulation rate based on the Dansgaard-Johnsen model (Dansgaard and Johnsen, 1969):

$$
a=\frac{2 H-h}{2 t} \ln \left(\frac{2 H-h}{2 z-h}\right), \quad h \leq z \leq H
$$

where $a$ is the average accumulation value from the time the layer was deposited until the present time, $H$ is ice thickness (assumed equal to present-day values), $h$ is the basal shear layer (where vertical strain is assumed to decrease linearly), $z$ is elevation above the bed and $t$ is time (i.e. the age of the layer). The Dansgaard-Johnsen model was developed for steady-state flow close to an ice divide, and depends among other things on a good approximation to $h$. We calculate the average accumulation rate in the part of the PIG basin where the $17.5 \mathrm{ka}$ layer was present using values of $h$ ranging from 100 to $1200 \mathrm{~m}$ (previous studies have used a value of $h=400 \mathrm{~m}$ for West Antarctica (Siegert and Payne, 2004)). This gives an accumulation rate ranging from 0.18 to $0.37 \mathrm{~m} \mathrm{a}^{-1}$. For comparison, the $3-\mathrm{D}$ model returns the correct age of the $17.5 \mathrm{ka}$ layer when the accumulation rate is set at $0.25 \mathrm{~m} \mathrm{a}^{-1}$, while Arthern and others (2006) suggest a modern-day accumulation rate of $0.36-0.37 \mathrm{ma}^{-1}$ using inversion techniques and observations.

Since layers 1 and 2 lie at a shallower depth than the ITASE-imaged $17.5 \mathrm{ka}$ layer they must be younger than $17.5 \mathrm{ka}$. From the three locations where the USITASE radar line intersects with PASIN profiles containing layer 2 (green arrows in Fig. 1) the mean vertical distance between layer 2 and the $17.5 \mathrm{ka}$ layer was $500 \mathrm{~m}$. In comparison the ice thicknesses in this area are 3000-3500 m (cf. Fig. 1a). Given that layer age increases exponentially towards the bed (e.g. Greve and others, 2002) it follows that, in fact, layer 2 is likely to be substantially younger than the 17.5 ka layer. To obtain an estimate of the age of the layer package we now apply the same simple relationship between layer depths and accumulation rates. We use the same range of $h$-values but the accumulation rates obtained from the $17.5 \mathrm{ka}$ layer are now used to calculate the age $t$, in the locations where layers 1 and 2 cross over the $17.5 \mathrm{ka}$ layer. This provides an age range for layer 1 of $5.3-6.2 \mathrm{ka}$ and for layer 2 of $8.6-13.4 \mathrm{ka}$.

An interesting link between the two strongly reflecting lower layers (where layer 2 is the upper of the two) emerges when comparing the age of layer 2 with acidity measurements of the Byrd ice core by Hammer and others (1997). In the interval between $9.7 \mathrm{ka}$ and the start of the acidity high that characterizes the $17.5 \mathrm{ka}$ layer (no measurements were made of the ages between 2.4 and $9.7 \mathrm{ka}$ ), two peaks stand out with acidities twice as high as in the other measurements. The two peaks correspond to ages of 10.2 and $11.4 \mathrm{ka}$, i.e. within the estimated age range of layer 2 . This study cannot confirm these as identical since that would require the spatial extent and reflectivity of the layers to be investigated, and the layers traced from the Byrd ice core to PIG, which is beyond the scope of this study. Future investigations of the PIG basin, especially if these also include areas in proximity to the Byrd ice core, might be able to identify and trace the layer package all the way to the Byrd ice core. This would pave the way for constructing a dated stratigraphy for the PIG basin, which could produce further insights into the past dynamics and accumulation of the area.

\section{DISCUSSION}

The results from the 3-D ice-flow model give some indications about past accumulation patterns. Firstly, the fact that the optimum parameters in our ice-sheet model for fitting layers 1 and 2 are not identical suggests a time dependence in the parameters. We suggest that this is most likely due to changes in accumulation pattern between the depositions of the two layers. Our results also indicate that the mean accumulation pattern of PIG has changed since the deposition of layer 1 since the modern-day accumulation pattern did not improve the fit compared to a uniform accumulation pattern. Based on these findings, we suggest that the accumulation pattern in the central PIG basin has changed at least twice between the time of deposition of layer 2 and the present day.

Our model results turned out to be insensitive even to a large increase in basal melt. This does not preclude the existence of basal melting in the region. Instead we suggest that if basal melting is present it is more likely to be controlled by the geothermal heat flux, in agreement with results from aerogravity measurements in the basin showing crustal thinning and thus the potential for elevated geothermal heat flux (Jordan and others, 2010). Even so, the geothermal heat flux is likely correlated with the basal topography, so it is surprising that our model results appear to be insensitive to changes in basal melting.

In order to obtain an approximate age range of the layers, we used the Dansgaard-Johnsen model (Eqn (7)) and the depth of a dated $17.5 \mathrm{ka}$ layer. We estimated an average accumulation rate between 0.18 and $0.37 \mathrm{~m} \mathrm{a}^{-1}$ for this layer. For comparison, using the same layer the 3-D model estimated an accumulation rate of $0.25 \mathrm{~m} \mathrm{a}^{-1}$. Other studies (Siegert and Payne, 2004) have investigated the fit of modelled accumulation with internal layering stratigraphy across the WAIS, and concluded that accumulation today is likely approximately double that which occurred between 6 and $16 \mathrm{ka}$ ago. Thus other parts of the WAIS have experienced changes in accumulation rate over similar timescales. Most likely the accumulation rate has not been steady over the PIG region during the past $17.5 \mathrm{ka}$, but tentatively our data indicate on average a similar or lower accumulation rate compared to the present day.

No other studies of past accumulation patterns for PIG exist. Studies from other parts of West Antarctica have found that accumulation rates are likely to have changed, but returned inconclusive results with regard to a change in accumulation pattern (e.g. Siple Dome (Nereson and others, 2000)). Neumann and others (2008) calculated accumulation rates across the WAIS ice divide and found evidence for changes in accumulation rate during the past $8 \mathrm{ka}$ but concluded that the spatial pattern of accumulation is unlikely to have changed significantly. The difference between previous studies and our findings is most likely a combination of the difference in spatial extent and the fact that even the central part of the PIG basin is more coastal than the other studies. It is therefore possible that the PIG dataset captures changes that previous datasets would not necessarily reflect both in terms of spatial extent and location.

If the estimated ages for the layers are approximately correct (5.3-6.2 ka for layer 1 and 8.6-13.4 ka for layer 2), then layer 2 could have been deposited at the beginning of the Holocene while the WAIS was retreating from its Last 
Glacial Maximum position to an extent closer to the present day (e.g. Hillenbrand and others, 2012) and where ice-core records show a widespread warming over the entire continent (Masson and others, 2000). It is well known that the accumulation pattern in Antarctica is controlled by distance from the coast, which is strongly correlated with surface elevation. It is therefore entirely possible that the changes in accumulation pattern accompanied - and maybe were a consequence of - the changes taking place at the margins of PIG during the transition in climate at the beginning of the Holocene, when the glacier retreated from the Amundsen Sea (e.g. Hillenbrand and others, 2012).

\section{CONCLUSION}

RES data from PIG show clear internal layering. In this study we have mapped a layer package in the central part of the catchment basin, where two layers could be traced across multiple flight lines. The two layers had depths below the ice surface ranging from 843 to $2359 \mathrm{~m}$ (layer 1 ) and 1124 to $2451 \mathrm{~m}$ (layer 2). The layer depths were used to extract information on past accumulation patterns by comparing the observed depths to outputs from a 3-D ice-flow model forced with different accumulation patterns.

Results from the 3-D ice-flow modelling indicated that there has been a change in accumulation pattern between present-day conditions and the deposition of layer 1 , and another change between the depositions of layers 1 and 2 . While basal melting may influence the depth of the layers, there was no obvious link between basal melt patterns and ice thickness.

The exact ages of the two layers traced in the RES dataset are not known, but using data from the 2001 USITASE survey that crossed into the basin, an indirect age constraint was obtained. The known age of a 17.5 ka layer from the Byrd ice core was used in a simple Dansgaard-Johnsen model, to obtain an average accumulation rate for the central part of the basin of $0.18-0.37 \mathrm{~m} \mathrm{a}^{-1}$ and age ranges of 5.3-6.2 $\mathrm{ka}$ for layer 1 and 8.6-13.4 ka for layer 2. We interpret this as an indication of similar or lower accumulation rates since the deposition of the 17.5 ka layer, and at least two changes in accumulation pattern in the central PIG basin during the past $10^{3}-10^{4}$ years. This indicates that the widespread retreat of PIG in the Amundsen Sea (e.g. Hillenbrand and others, 2012) at the end of the Last Glacial Maximum and the beginning of the Holocene was accompanied by changes in accumulation pattern and potentially accumulation rate.

Future RES work in this region of West Antarctica should consider targeting the layer package and link it to the Byrd ice core. In this way a better-dated stratigraphy for the PIG basin could be constructed. At the moment, however, the nature of the RES dataset at hand precludes the identification of layers between flight lines, making them of limited use to modelling efforts. This is why the identification and tracing of the layer package adds substantial value to the RES data.

\section{ACKNOWLEDGEMENTS}

We acknowledge logistical support for the field campaign from the British Antarctic Survey, the University of Texas and the US National Science Foundation. We thank the field party, and L. Byrne, who digitized the RES data. We gratefully acknowledge reviewers $M$. Koutnik and R. Drews whose extensive comments and feedback substantially improved the quality of the manuscript.

\section{REFERENCES}

Arthern RJ, Winebrenner DP and Vaughan DG (2006) Antarctic snow accumulation mapped using polarization of $4.3-\mathrm{cm}$ wavelength microwave emission. J. Geophys. Res., 111(D6), D06107 (doi: 10.1029/2004JD005667)

Bamber JL, Riva REM, Vermeersen BLA and LeBrocq AM (2009) Reassessment of the potential sea-level rise from a collapse of the West Antarctic Ice Sheet. Science, 324(5929), 901-903 (doi: 10.1126/science.1169335)

Bingham RG, Siegert MJ, Young DA and Blankenship DD (2007) Organized flow from the South Pole to the Filchner-Ronne ice shelf: an assessment of balance velocities in interior East Antarctica using radio echo sounding data. J. Geophys. Res., 112(F3), F03S26 (doi: 10.1029/2006JF000556)

Blunier T and Brook EJ (2001) Timing of millennial-scale climate change in Antarctica and Greenland during the last glacial period. Science, 291(5501), 109-112 (doi: 10.1126/science. 291.5501.109)

Buchardt S and Dahl-Jensen D (2007) Estimating the basal melt rate at NorthGRIP using a Monte Carlo technique. Ann. Glaciol., 45, 137-142 (doi: 10.3189/172756407782282435)

Corr $\mathrm{H}$ and 8 others (2007) Airborne radio-echo sounding of the Wilkes Subglacial Basin, the Transantarctic Mountains, and the Dome C region. Terra Antart. Rep. 13, 55-64

Cuffey KM and Paterson WSB (2010) The physics of glaciers, 4th edn. Butterworth-Heinemann, Oxford

Dansgaard W and Johnsen SJ (1969) A flow model and a time scale for the ice core from Camp Century, Greenland. J. Glaciol., 8(53), 215-223

Eisen O, Hamann I, Kipfstuhl S, Steinhage D and Wilhelms F (2007) Direct evidence for continuous radar reflector originating from changes in crystal-orientation fabric. Cryosphere, 1(1), 1-10 (doi: 10.5194/tc-1-1-2007)

Fretwell P and 59 others (2013) Bedmap2: improved ice bed, surface and thickness datasets for Antarctica. Cryosphere, 7(1) 375-393 (doi: 10.5194/tc-7-375-2013)

Frezzotti M, Scarchilli C, Becagli S, Proposito M and Urbini S (2013) A synthesis of the Antarctic surface mass balance during the last 800 yr. Cryosphere, 7(1), 303-319 (doi: 10.5194/tc-7-303-2013)

Fujita $S$ and 6 others (1999) Nature of radio-echo layering in the Antarctic ice sheet detected by a two-frequency experiment. J. Geophys. Res., 104(B6), 13 013-13024

Gladstone RM and 9 others (2012) Calibrated prediction of Pine Island Glacier retreat during the 21 st and 22 nd centuries with a coupled flowline model. Earth Planet. Sci. Lett., 333-334, 191-199 (doi: 10.1016/j.epsl.2012.04.022)

Glen JW (1955) The creep of polycrystalline ice. Proc. R. Soc. London, Ser. A, 228(1175), 519-538 (doi: 10.1098/rspa.1955. 0066)

Greve R, Wang Y and Mügge B (2002) Comparison of numerical schemes for the solution of the advective age equation in ice sheets. Ann. Glaciol., 35, 487-494 (doi: 10.3189/172756402781817112)

Hammer CU, Clausen HB and Langway CC Jr (1997) 50,000 years of recorded global volcanism. Climatic Change, 35(1), 1-15 (doi: 10.1023/A:1005344225434)

Haran T, Bohlander J, Scambos T, Painter T and Fahnestock M (2006) MODIS mosaic of Antarctica (MOA) image map. National Snow and Ice Data Center, Boulder, CO. Digital media: http://nsidc.org/data/nsidc-0280

Hillenbrand C-D and 10 others (2012) Grounding-line retreat of the West Antarctic Ice Sheet from inner Pine Island Bay. Geology, 41(1), 35-38 (doi: 10.1130/G33469.1)

Hindmarsh RCA, Leysinger Vieli GJM and Parrenin F (2009) A large-scale numerical model for computing isochrone 
geometry. Ann. Glaciol., 50(51), 130-140 (doi: 10.3189/ 172756409789097450)

Holt JW and 8 others (2006) New boundary conditions for the West Antarctic Ice Sheet: subglacial topography of the Thwaites and Smith glacier catchments. Geophys. Res. Lett., 33(9), L09502 (doi: 10.1029/2005GL025561)

Hughes TJ (1981) Correspondence. The weak underbelly of the West Antarctic ice sheet. J. Glaciol., 27(97), 518-525

Hutter K (1983) Theoretical glaciology; material science of ice and the mechanics of glaciers and ice sheets. D. Reidel, Dordrecht/ Terra Scientific, Tokyo

Huybrechts P, Rybak O, Steinhage D and Pattyn F (2009) Past and present accumulation rate reconstruction along the Dome Fuji-Kohnen radio-echo sounding profile, Dronning Maud Land, East Antarctica. Ann. Glaciol., 50(51), 112-120 (doi: 10.3189/ 172756409789097513)

Jacobel RW and Welch BC (2005) A time marker at $17.5 \mathrm{ka} \mathrm{BP}$ detected throughout West Antarctica. Ann. Glaciol., 41, 47-51 (doi: 10.3189/172756405781813348)

Jordan TA and 6 others (2010) Aerogravity evidence for major crustal thinning under the Pine Island Glacier region (West Antarctica). Geol. Soc. Am. Bull., 122(5-6), 714-726 (doi: 10.1130/B26417.1)

Joughin I and Alley RB (2011) Stability of the West Antarctic ice sheet in a warming world. Nature Geosci., 4(8), 506-513 (doi: 10.1038/ngeo1194)

Joughin I, Smith BE and Holland DM (2010) Sensitivity of 21st century sea level to ocean-induced thinning of Pine Island Glacier, Antarctica. Geophys. Res. Lett., 37(20), L20502 (doi: 10.1029/2010GL044819)

Karlsson NB, Rippin DM, Vaughan DG and Corr HFJ (2009) The internal layering of Pine Island Glacier, West Antarctica, from airborne radar-sounding data. Ann. Glaciol., 50(51), $141-146$

Karlsson NB, Rippin DM, Bingham RG and Vaughan DG (2012) A 'continuity-index' for assessing ice-sheet dynamics from radarsounded internal layers. Earth Planet. Sci. Lett., 335-336, 88-94 (doi: 10.1016/j.epsl.2012.04.034)

King MA, Bingham RJ, Moore P, Whitehouse PL, Bentley MJ and Milne GA (2012) Lower satellite-gravimetry estimates of Antarctic sea-level contribution. Nature, 491(7425), 586-589 (doi: 10.1038/nature11621)

Larour E, Schiermeier J, Rignot E, Seroussi H, Morlighem M and Paden J (2012) Sensitivity analysis of Pine Island Glacier ice flow using ISSM and DAKOTA. J. Geophys. Res., 117(F2), F02009 (doi: 10.1029/2011JF002146)

Leysinger Vieli GJM, Hindmarsh RCA and Siegert MJ (2007) Threedimensional flow influences on radar layer stratigraphy. Ann. Glaciol., 46, 22-28 (doi: 10.3189/172756407782871729)

Leysinger Vieli GJMC, Hindmarsh RCA, Siegert MJ and Bo S (2011) Time-dependence of the spatial pattern of accumulation rate in East Antarctica deduced from isochronic radar layers using a 3-D numerical ice flow model. J. Geophys. Res., 116(F2), F02018 (doi: 10.1029/2010JF001785)

MacGregor JA, Matsuoka K, Koutnik MR, Waddington ED, Studinger M and Winebrenner DP (2009) Millennially averaged accumulation rates for the Vostok Subglacial Lake region inferred from deep internal layers. Ann. Glaciol., 50(51), 2534 (doi: 10.3189/172756409789097441)

Masson V and 13 others (2000) Holocene climate variability in Antarctica based on 11 ice-core isotopic records. Quat. Res., 54(3), 348-358 (doi: 10.1006/qres.2000.2172)

Mercer JH (1978) West Antarctic ice sheet and $\mathrm{CO}_{2}$ greenhouse effect: a threat of disaster. Nature, 271(5643), 321-325 (doi: $10.1038 / 271321 \mathrm{a} 0)$

Miller DHM (1981) Radio-echo layering in polar ice sheets and past volcanic activity. Nature, 292(5822), 441-443 (doi: 10.1038/ 292441a0)

Nereson NA, Raymond CF, Jacobel RW and Waddington ED (2000) The accumulation pattern across Siple Dome, West Antarctica, inferred from radar-detected internal layers. J. Glaciol., 46(152), 75-87 (doi: 10.3189/172756500781833449)

Neumann TA, Conway H, Waddington E, Catania GA and Morse DL (2008) Holocene accumulation and ice sheet dynamics in central West Antarctica. J. Geophys. Res., 113(F2), F02018 (doi: 10.1029/2007JF000764)

$\mathrm{Ng} \mathrm{F}$ and Conway H (2004) Fast-flow signature in the stagnated Kamb Ice Stream, West Antarctica. Geology, 32(6), 481-484 (doi: 10.1130/G20317.1)

Park JW, Gourmelen N, Shepherd A, Kim SW, Vaughan DG and Wingham DJ (2013) Sustained retreat of the Pine Island Glacier. Geophys. Res. Lett., 40(10), 2137-2142 (doi: 10.1002/grl.50379)

Parrenin F, Rémy F, Ritz C, Siegert MJ and Jouzel J (2004) New modeling of the Vostok ice flow line and implication for the glaciological chronology of the Vostok ice core. J. Geophys. Res., 109(D20), D20102 (doi: 10.1029/2004JD004561)

Parrenin F, Hindmarsh RCA and Rémy F (2006) Analytical solutions for the effect of topography, accumulation rate and lateral flow divergence on isochrone layer geometry. J. Glaciol., 52(177), 191-202 (doi: 10.3189/172756506781828728)

Paterson WSB (1994) The physics of glaciers, 3rd edn. Elsevier, Oxford

Pritchard HD, Arthern RJ, Vaughan DG and Edwards LA (2009) Extensive dynamic thinning on the margins of the Greenland and Antarctic ice sheets. Nature, 461(7266), 971-975 (doi: 10.1038/nature08471)

Rignot EJ (1998) Fast recession of a West Antarctic glacier. Science, 281(5376), 549-551 (doi: 10.1126/science.281.5376.549)

Rignot E (2006) Changes in ice dynamics and mass balance of the Antarctic ice sheet. Philos. Trans. R. Soc. London, Ser. A, 364(1844), 1637-1655 (doi: 10.1098/rsta.2006.1793)

Rignot E and 6 others (2008) Recent Antarctic ice mass loss from radar interferometry and regional climate modelling. Nature Geosci., 1(2), 106-110 (doi: 10.1038/ngeo102)

Rippin DM, Siegert MJ and Bamber JL (2003) The englacial stratigraphy of Wilkes Land, East Antarctica, as revealed by internal radio-echo sounding layering, and its relationship with balance velocities. Ann. Glaciol., 36, 189-196 (doi: 10.3189/ 172756403781816356)

Ross N and 9 others (2012) Steep reverse bed slope at the grounding line of the Weddell Sea sector in West Antarctica. Nature Geosci., 5(6), 393-396 (doi: 10.1038/ngeo1468)

Scott JBT, Gudmundsson GH, Smith AM, Bingham RG, Pritchard HD and Vaughan DG (2009) Increased rate of acceleration on Pine Island Glacier strongly coupled to changes in gravitational driving stress. Cryosphere, 3(1), 125-131 (doi: 10.5194/tc-3125-2009)

Shepherd A, Wingham D and Mansley JA (2002) Inland thinning of the Amundsen Sea sector, West Antarctica. Geophys. Res. Lett., 29(10), 1364 (doi: 10.1029/2001GL014183)

Siegert MJ (1999) On the origin, nature and uses of Antarctic icesheet radio-echo layering. Progr. Phys. Geogr., 23(2), 159-179 (doi: 10.1177/030913339902300201)

Siegert MJ and Payne AJ (2004) Past rates of accumulation in central West Antarctica. Geophys. Res. Lett., 31(12), L12403 (doi: 10.1029/2004GL020290)

Smith AM, Bentley CR, Bingham RG and Jordan TA (2012) Rapid subglacial erosion beneath Pine Island Glacier, West Antarctica. Geophys. Res. Lett., 39(12), L12501 (doi: 10.1029/ 2012GL051651)

Smith AM, Jordan TA, Ferraccioli F and Bingham RG (2013) Influence of subglacial conditions on ice stream dynamics: seismic and potential field data from Pine Island Glacier, West Antarctica. J. Geophys. Res., 118(B4), 1471-1482 (doi: 10.1029/ 2012JB009582)

Thomas R and 17 others (2004) Accelerated sea-level rise from West Antarctica. Science, 306(5694), 255-258 (doi: 10.1126/ science.1099650)

Van de Berg WJ, Van den Broeke MR, Reijmer $\mathrm{CH}$ and Van Meijgaard E (2006) Reassessment of the Antarctic surface mass 
balance using calibrated output of a regional atmospheric climate model. J. Geophys. Res., 111(D11), D11104 (doi: 10.1029/2005JD006495)

Vaughan DG and 9 others (2006) New boundary conditions for the West Antarctic ice sheet: subglacial topography beneath Pine Island Glacier. Geophys. Res. Lett., 33(9), L09501 (doi: 10.1029/ 2005GL025588)

Waddington ED, Neumann TA, Koutnik MR, Marshall H-P and Morse DL (2007) Inference of accumulation-rate patterns from deep layers in glaciers and ice sheets. J. Glaciol., 53(183), 694-712 (doi: 10.3189/002214307784409351)

Welch BC and Jacobel RW (2003) Analysis of deep-penetrating radar surveys of West Antarctica, US-ITASE 2001. Geophys. Res. Lett., 30(8), 1444 (doi: 10.1029/2003GL017210)

Wingham DJ, Wallis DW and Shepherd A (2009) Spatial and temporal evolution of Pine Island Glacier thinning, 1995-2006. Geophys. Res. Lett., 36(17), L17501 (doi: 10.1029/ 2009GL039126)

MS received 17 September 2013 and accepted in revised form 9 April 2014 